\title{
Reproduction in grazing dairy cows treated with 14-day controlled internal drug release for presynchronization before timed artificial insemination compared with artificial insemination after observed estrus
}

\author{
R. C. Escalante, S. E. Poock, D. J. Mathew, W. R. Martin, E. M. Newsom, S. A. Hamilton, K. G. Pohler, \\ and M. C. Lucy ${ }^{1}$ \\ Division of Animal Sciences and College of Veterinary Medicine, University of Missouri, Columbia 65211
}

\begin{abstract}
Progesterone-releasing (controlled internal drug release, CIDR) devices inserted for $14 \mathrm{~d}$ are used to presynchronize the estrous cycle for timed artificial insemination (TAI) in beef heifers (14-d CIDR-PGF $2 \alpha$ program). The objective was to test a similar program in dairy cows by measuring first-service conception rates (FSCR), pregnancy rates after $2 \mathrm{AI}$, and time to pregnancy compared with a control (AI after observed estrus). Postpartum cows (Holstein, Jersey, or crossbred; $\mathrm{n}=1,363$ ) from 4 grazing dairy farms were assigned to 1 of 2 programs: 14dCIDR_TAI [CIDR in for $14 \mathrm{~d}$, CIDR out, $\mathrm{PGF}_{2 \alpha}$ injection at $19 \mathrm{~d}$ after CIDR removal, GnRH injection $56 \mathrm{~h}$ later, and then TAI 16 $\mathrm{h}$ later; $\mathrm{n}=737$ ] or control [AI after observed estrus; reproductive program with $\mathrm{PGF}_{2 \alpha}$ (cycling cows) and CIDR (noncycling cows) to synchronize estrus with the start of the breeding season; $\mathrm{n}=626]$. Body condition was scored ( 1 to 5 ; thin to fat) at the start of the trial. The interval from the start of the breeding period (final $\mathrm{PGF}_{2 \alpha}$ injection of either program) to first AI was shorter for 14dCIDR_TAI compared with the control $(3.0 \pm 0.2$ vs. $5.3 \pm 0.2 \mathrm{~d}$; mean $\pm \mathrm{SEM})$ but 14dCIDR_TAI cows had lesser FSCR than controls (48 vs. 61\%). Farm affected FSCR (50, 51, 67, and 58\% for farms 1 to 4$)$. The BCS affected FSCR (50, 55, and $62 \%$ for $\mathrm{BCS}=2,2.5$, and 3 , respectively). Cows that either calved the year before (carryover) or that calved early in the calving season had greater FSCR than cows that calved later in the calving season $(55,61$, and $42 \%$, respectively). The percentage of cows pregnant to AI (first and second inseminations within 31-d breeding season) was similar for 14dCIDR_TAI and control (64 vs. $70 \%)$ cows, but farm $(64,62,80$, and $69 \%)$ and time of calving (70, 76, and 56\%: carryover, early, and late, respectively) affected the percentage. Survival analyses showed an initial advantage for 14dCIDR_TAI (more
\end{abstract}

Received June 19, 2012.

Accepted September 20, 2012.

${ }^{1}$ Corresponding author: lucym@missouri.edu cows inseminated and more pregnancies achieved early in the breeding season) that was not maintained over time. Conclusions were that the $14 \mathrm{dCIDR}$-TAI program achieved acceptable FSCR $(48 \%)$ and overall AI pregnancy rates $(64 \%)$, but did not surpass a control program that used AI after observed estrus (61 and $70 \%$, respectively).

Key words: dairy cow, timed artificial insemination, grazing

\section{INTRODUCTION}

Seasonal grazing dairy cows should be inseminated and pregnant by $80 \mathrm{~d}$ postpartum so that they calve within a year-long interval (Lucy et al., 2004). Intensive reproductive management of first and second insemination can be applied to increase the likelihood of an optimal time of insemination so that the desired calving interval is achieved. Some reproductive management programs synchronize estrus at the start of breeding season. Insemination following an observed estrus can be difficult because cows may have a reduced expression of estrous behavior or personnel may be unable to detect estrus (Macmillan, 2010). Synchronization of ovulation followed by timed AI (TAI), therefore, has become more common (Macmillan, 2010). Synchronization of ovulation followed by TAI may improve reproductive efficiency by reducing the interval to first insemination, the interval between inseminations, and the interval to pregnancy. Pursley et al. (1997a) demonstrated that cows inseminated by TAI after synchronized ovulation were more likely to become pregnant by $100 \mathrm{~d}$ postpartum compared with cows that were inseminated after estrus.

Several reproductive programs use a luteolytic dose of $\mathrm{PGF}_{2 \alpha}$ to synchronize estrus. Programs that are $\mathrm{PGF}_{2 \alpha}$-based require estrus detection for 5 to $7 \mathrm{~d}$ after the injection of $\mathrm{PGF}_{2 \alpha}$ (Cavalieri et al., 2006). Cows that do not come into estrus after a $\mathrm{PGF}_{2 \alpha}$ injection may either be noncycling, may have a corpus luteum (CL) that is immature and will not regress, or may have a dominant follicle that is immature and not ca- 
pable of causing estrus and ovulating. Administering a second dose of $\mathrm{PGF}_{2 \alpha} 1$ to 2 wk afterward to those cows that did not come into estrus could potentially cause those cows that had an immature CL to regress their CL and come into estrus.

The traditional programs to synchronize ovulation before TAI are Presynch-Ovsynch (Moreira et al., 2001), Double Ovsynch (Giordano et al., 2012), and G6G (Bello et al., 2006; Ribeiro et al., 2011). Another method that can be used to synchronize ovulation is a long-term progestogen treatment. This method was effective in beef heifers and beef cows (Schafer et al., 2007; Leitman et al., 2009). The use of long-term progestogens, such as a controlled internal drug release (CIDR) device (Pfizer Animal Health Inc., New York, NY) for $14 \mathrm{~d}$, will suppress estrus, inhibit ovulation, and induce the development of a persistent dominant follicle that can ovulate after CIDR removal (Ahmad et al., 1995; Revah and Butler, 1996; Roche et al., 1999). Ovulation of the dominant follicle creates a synchronized estrous cycle that can be used as the Presynch step within a TAI program. In this case, $\mathrm{PGF}_{2 \alpha}$ is injected 16 to 19 $\mathrm{d}$ after CIDR removal and followed by GnRH injection (56 h later) and TAI (16 h after GnRH injection). The objective was to evaluate pregnancies per AI after 2 reproductive programs: one involving synchronization of ovulation followed by TAI (14dCIDR_TAI) and the other involving a $\mathrm{PGF}_{2 \alpha}$-based program of synchronization of estrus followed by estrus detection and AI.

\section{MATERIALS AND METHODS}

\section{Farms and Animals}

Postpartum dairy cows from 4 grazing dairy farms [farm $1(\mathrm{n}=543)$, farm $2(\mathrm{n}=514)$, farm $3(\mathrm{n}=$ 235), and farm $4(\mathrm{n}=71)$ ] located in southwest Missouri were used. The trial was conducted during March through June 2011. The farms were spring-calving seasonal pasture-based systems with an annual dry-off in December and calving season from February to March. Cows were kept on pasture containing cereal ryegrass from February to April and on endophyte fescue and perennial ryegrass from April to July. All cows were milked twice per day and were supplemented with concentrate (ground corn) during morning milking. Cows were either Holstein $(\mathrm{n}=803)$, Jersey $(\mathrm{n}=122)$, or crossbred $(\mathrm{n}=438)$. Cows enrolled in the trial were defined as early spring calving (calved on or before March 1; $\mathrm{n}=478$ ), late spring calving (calved after March 1; $\mathrm{n}=219$ ), or carryover (calved the year before and inseminated in the spring; $\mathrm{n}=148)$. Five hundred eighteen cows had unknown calving dates.

\section{Synchronization and TAI}

Cows were assigned to 1 of 2 programs (Figure 1 ). Cows had to be at least $10 \mathrm{~d}$ postpartum to be started on the trial. For the spring-calving cows, the mean \pm standard deviation of days postpartum at the start of the trial was $35 \pm 11 \mathrm{~d}$. For carryover cows, the mean \pm standard deviation of days postpartum at the start of the trial was $383 \pm 18 \mathrm{~d}$. The days postpartum were similar for 14dCIDR_TAI and control programs $(P>$ $0.10)$. The $14 \mathrm{dCIDR}$ _TAI cows $(\mathrm{n}=737)$ were treated with an intravaginal CIDR device (EAZI-BREED CIDR containing $1.38 \mathrm{~g}$ of progesterone; Pfizer Animal Health Inc.) on d 0 for $14 \mathrm{~d}$. At $19 \mathrm{~d}$ after CIDR removal, cows were treated with $\mathrm{PGF}_{2 \alpha}$ (5 mL of Lutalyse i.m.; 25 $\mathrm{mg}$ of dinoprost tromethamine; Pfizer Animal Health Inc.); $56 \mathrm{~h}$ later, they were treated with $\mathrm{GnRH}(2 \mathrm{~mL}$ of Factrel i.m.; $100 \mu \mathrm{g}$ of gonadorelin hydrochloride; Pfizer Animal Health Inc.), and then $16 \mathrm{~h}$ later with TAI. Ninety-five cows (12.9\%) were in estrus before the TAI. These cows were inseminated when observed in estrus. Nineteen $(2.6 \%)$ were also accidently omitted from the TAI and were artificially inseminated when seen in estrus during the breeding season.

The control cows $(\mathrm{n}=626)$ were treated with $\mathrm{PGF}_{2 \alpha}$ on d 12 and tail painted; $7 \mathrm{~d}$ later, cows that did not come into estrus (tail paint not rubbed off) were treated with $\mathrm{PGF}_{2 \alpha}$ and tail painted again; $7 \mathrm{~d}$ later cows that did not come into estrus from the first or second $\mathrm{PGF}_{2 \alpha}$ injection were treated with a CIDR for $7 \mathrm{~d}$. Seven days later, the CIDR was pulled and cows that came into estrus from the second $\mathrm{PGF}_{2 \alpha}$ and that were treated with a CIDR were treated again with $\mathrm{PGF}_{2 \alpha}$. Cows were then tail painted. Cows were artificially inseminated based on estrus (visual detection or tail paint rubbed off indicating estrus). Cows were body condition scored on a scale from 1 to 5 (thin to fat) at the start of the trial.

\section{Second Insemination and Pregnancy Diagnosis}

The individual farms used an estrus-detection program after the first AI. The programs consisted of visual observation of estrus and also tail paint scoring. Cows were artificially inseminated if they were observed in estrus or their tail paint was rubbed off. Second insemination dates were recorded. Pregnancy diagnosis was performed by using transrectal ultrasonography (Easi-Scan; BCF Technology USA Ltd. LLC, Rochester, MN) 51 to $56 \mathrm{~d}$ after the TAI date. Conception date was based on fetal size (crown rump length). Cows pregnant to first AI and second AI were determined. All cows in the 14dCIDR TAI program had a first AI, but 25 cows in the control 


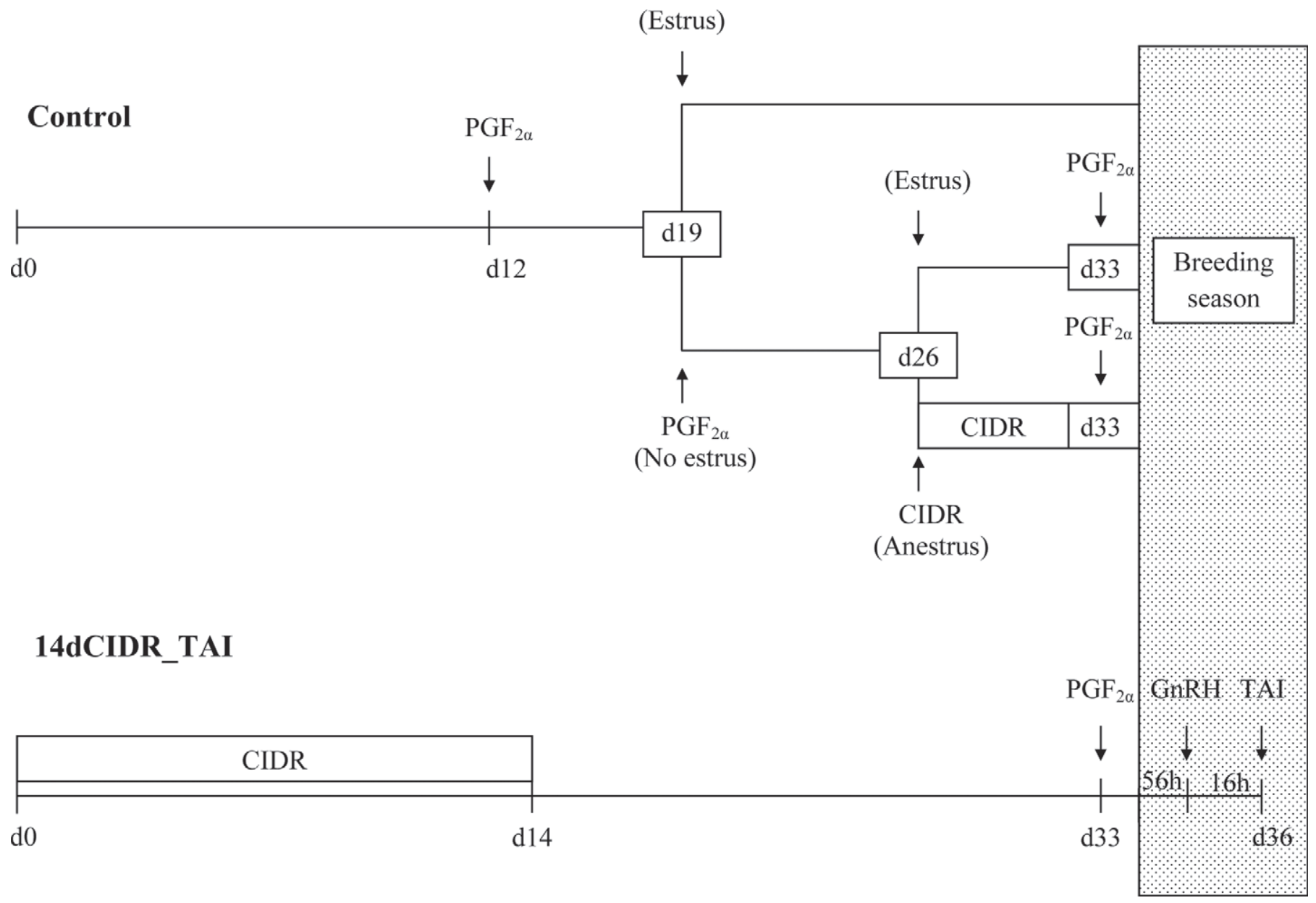

Figure 1. Timeline for treatment administration for cows assigned to 14dCIDR_TAI and control programs, where 14dCIDR_TAI $=$ controlled internal drug release $(\mathrm{CIDR})$ device in for $14 \mathrm{~d}$, CIDR out, $\mathrm{PGF}_{2 \alpha}$ injection at $19 \mathrm{~d}$ after CIDR removal, GnRH injection $56 \mathrm{~h}$ later, and then timed $\mathrm{AI}$ (TAI) $16 \mathrm{~h}$ later; and control $=\mathrm{PGF}_{2 \alpha}$ injection on $\mathrm{d} 12, \mathrm{PGF}_{2 \alpha}$ treatment again to cows with no estrus $7 \mathrm{~d}$ later, $\mathrm{CIDR}$ to cows with no estrus after the first or second $\mathrm{PGF}_{2 \alpha}$ injection $7 \mathrm{~d}$ later, CIDR out and $\mathrm{PGF}_{2 \alpha}$ treatment again $7 \mathrm{~d}$ later, and $\mathrm{AI}$ after observed estrus. $\mathrm{CIDR}=$ intravaginal CIDR (1.38 g of progesterone; Pfizer Animal Health Inc., New York, NY); PGF $2 \alpha=5 \mathrm{~mL}$ of Lutalyse (i.m.; 25 mg of dinoprost tromethamine; Pfizer Animal Health Inc.); $\mathrm{GnRH}=2 \mathrm{~mL}$ of Factrel (Pfizer Animal Health Inc.); breeding season $=$ AI after observed estrus.

program were never artificially inseminated. If a cow had not received a first or second insemination or was less than $25 \mathrm{~d}$ after first or second insemination when she was pregnancy diagnosed, then she was not included in the analyses of first or second AI conception rate respectively. The total number of pregnancies after first and second AI was based on known pregnancies at the time of pregnancy diagnosis (the cow had to be at least $25 \mathrm{~d}$ pregnant). Twenty-one cows (13 14dCIDR_TAI and 8 control cows) were at less than $25 \mathrm{~d}$ since their insemination at the time of pregnancy diagnosis. These cows, if pregnant, did not contribute to the total number of pregnancies in the analyses.

\section{Statistical Analyses}

Body condition scores were coded as 2 (cows with score 2 to 2.25 ), 2.5 (cows with score 2.5 to 2.75 ), or 3 (cows with score 3.0 to 3.25 ) for the purpose of statistical analysis. Pregnant cows were coded as 1 (pregnant) or 0 (not pregnant) to the respective insemination dates. Pregnancy status was analyzed as the discrete dependent variable. Treatment, farm, AI technician, AI sire, breed, calving date (early, late, carryover, or unknown), and BCS $(2,2.5$, or 3$)$ were classified as independent variables. The generalized linear model (PROC GENMOD) of SAS (SAS Institute Inc., Cary, NC) was used for the statistical analysis. The product-limit survival estimates of cows that were not artificially inseminated and not pregnant on a given day of the breeding season were tested by using the LIFETEST procedure of SAS. The log-rank $P$-value for the LIFETEST procedure was used for the test of significance. Statistical significance was declared at $P \leq 0.05$. Statistical tendency was defined as $0.05<P \leq 0.10$. 
Table 1. First AI and second AI conception rate and overall pregnancy rate (with percentages in parentheses) for cows treated with different reproductive programs ${ }^{1}$

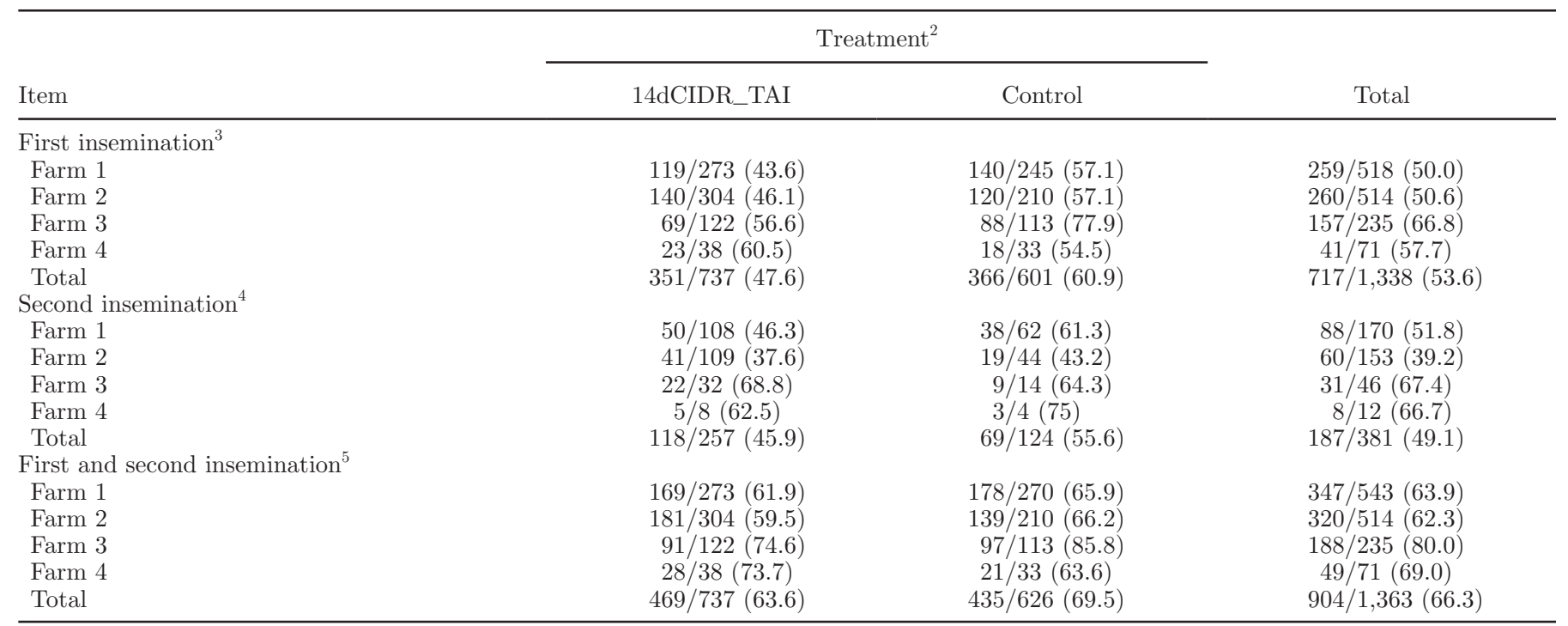

${ }^{1}$ The 14dCIDR_TAI program used a controlled internal drug release (CIDR) device containing $1.38 \mathrm{~g}$ of progesterone (EAZI-BREED CIDR; Pfizer Animal Health Inc., New York, NY) to presynchronize the estrous cycle before a timed AI (TAI), and the control used a PGF ${ }_{2 \alpha}-$ based program to synchronize estrus before AI.

${ }^{2} 14 \mathrm{dCIDR} \_\mathrm{TAI}=\mathrm{CIDR}$ in for $14 \mathrm{~d}, \mathrm{CIDR}$ out, $\mathrm{PGF}_{2 \alpha}$ injection at $19 \mathrm{~d}$ after CIDR removal, GnRH injection $56 \mathrm{~h}$ later, and then TAI $16 \mathrm{~h}$ later; control $=\mathrm{PGF}_{2 \alpha}$ injection on $\mathrm{d} 12, \mathrm{PGF}_{2 \alpha}$ treatment again to cows with no estrus $7 \mathrm{~d}$ later, CIDR to cows with no estrus after the first or second $\mathrm{PGF}_{2 \alpha}$ injection $7 \mathrm{~d}$ later, CIDR out and $\mathrm{PGF}_{2 \alpha}$ treatment again $7 \mathrm{~d}$ later, and $\mathrm{AI}$ after observed estrus.

${ }^{3}$ Number of pregnant cows after first insemination/total number of cows inseminated.

${ }^{4}$ Number of pregnant cows after second insemination/total number of cows that received a second insemination.

${ }^{5}$ Total number of pregnant cows/total number of cows.

\section{RESULTS}

\section{Pregnancies per Al}

No effect $(P>0.05)$ was observed of AI technician, AI sire, or breed on first AI conception rate (number of pregnant cows/number of AI: 717/1,338; 53.6\%), on second AI conception rate $(187 / 381 ; 49.1 \%)$, or on the total number of pregnancies at the end of the first and second AI (number of pregnant cows/total cows: $904 / 1,363 ; 66.3 \%)$. An effect of treatment $(P<0.05)$ on first-service conception rate (FSCR) was observed. Cows treated with14dCIDR_TAI $(351 / 737 ; 47.6 \%)$ had lesser FSCR than the control cows $(366 / 601$; $60.9 \%)$. An effect was observed of farm $(P<0.001)$ on FSCR [farm 1 (259/518; 50.0\%), farm 2 (260/514; $50.6 \%)$, farm $3(157 / 235 ; 66.8 \%)$, and farm $4(41 / 71$; $57.7 \%)]$ and a tendency for a treatment by farm interaction $(P<0.10)$. No effect $(P>0.05)$ existed of treatment or farm on second insemination conception rate. No effect $(P>0.05)$ was observed of treatment on the percentage of pregnant cows after first and second AI. An effect existed, however, of farm $(P<$ 0.001 ) on the percentage of pregnant cows [first and second AI; farm 1 (347/543; 63.9\%), farm 2 (320/514;
$62.3 \%)$, farm $3(188 / 235 ; 80.0 \%)$, and farm $4(49 / 71$; $69.0 \%$; Table 1].

\section{BCS and Calving Status}

The average BCS for cows on farms 1, 2, 3, and 4 was $2.4 \pm 0.01,2.2 \pm 0.01,2.3 \pm 0.02$ and $2.4 \pm$ 0.04 (farm 2 had lesser BCS than the other 3 farms; $P<0.05$, Duncan's multiple range test). The FSCR increased with increasing BCS $(50,55$, and $62 \%$ for cows with $\mathrm{BCS}=2.0,2.5$, and 3.0, respectively; $P<$ 0.05 ; Figure 2). The interaction of treatment and BCS was not significant for FSCR $(P<0.10)$. No effect $(P$ $>0.05)$ was observed of BCS on second insemination conception rate. An effect $(P<0.05)$ was observed of BCS on the percentage of pregnant cows (first and second AI, combined) because the percentage of pregnant cows increased for BCS $=2,2.5$, and 3 (63.7, 69.4, and $75.7 \%$, respectively).

An effect was observed of calving status on FSCR ( $P$ $<0.001$ ). Cows that either calved the year before (carryover; $55 \%)$ or that calved early $(61 \%)$ in the calving season had greater FSCR than cows that calved later in the calving season (42\%; Figure 3$)$. No effect $(P>0.05)$ existed of calving status on second AI conception rate. 


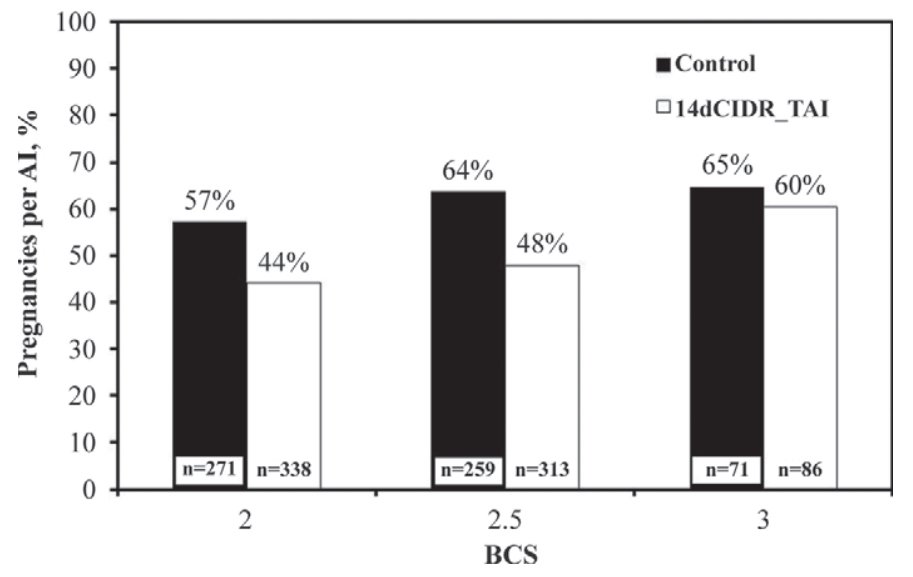

Figure 2. First-service conception rate (number of pregnant cows/the number of AI; pregnancies per AI) for cows in the control and $14 \mathrm{dCIDR}$ TAI programs that had a BCS of $2,2.5$, or 3 , where $14 \mathrm{dCIDR} \_$TAI $=$controlled internal drug release $(\mathrm{CIDR})$ device in for $14 \mathrm{~d}$, CIDR out, $\mathrm{PGF}_{2 \alpha}$ injection at $19 \mathrm{~d}$ after CIDR removal, GnRH injection $56 \mathrm{~h}$ later, and then timed AI (TAI) $16 \mathrm{~h}$ later; and control $=\mathrm{PGF}_{2 \alpha}$ injection on $\mathrm{d} 12, \mathrm{PGF}_{2 \alpha}$ treatment again to cows with no estrus $7 \mathrm{~d}$ later, CIDR to cows with no estrus after the first or second $\mathrm{PGF}_{2 \alpha}$ injection $7 \mathrm{~d}$ later, CIDR out and $\mathrm{PGF}_{2 \alpha}$ treatment again $7 \mathrm{~d}$ later, and AI after observed estrus. The conception rate increased with increasing BCS $(P<0.05)$. The interaction of BCS and treatment was not significant.

An effect was observed of calving status on the percentage of pregnant cows after first and second $\mathrm{AI}(P<$ 0.001 ). The carryover cows had a final pregnancy rate of $69.6 \%$. The comparable numbers for early calving and late-calving cows was 76.2 and $56.6 \%$, respectively.

\section{Survival Analysis of Interval to First Insemination and Interval to Pregnancy}

Survival analyses were used to test the effects of treatment on the proportion of cows not AI on each day during the breeding season (Figure 4). The cows treated with the 14dCIDR_TAI program had more inseminations earlier in the breeding season compared with the control program $(P<0.001)$. Survival analyses were also used to test the effect of treatment on the proportion of cows not pregnant on each day during the breeding season. The 14dCIDR_TAI program achieved more pregnancies earlier in the breeding season compared with the control program, but this effect was not maintained throughout the breeding season (curves differed at $P<0.01$; Figure 5).

\section{DISCUSSION}

We compared a novel 14dCIDR_TAI program to a control program that used AI after estrus. The 14dCIDR program is similar to programs that use oral administration of melengestrol acetate (MGA) for 14

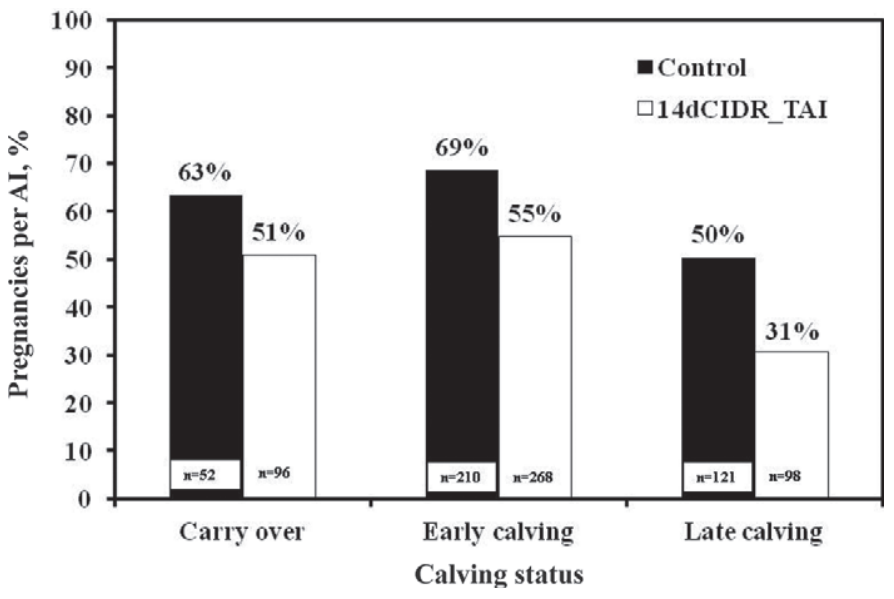

Figure 3. First-service conception rate (number of pregnant cows/ the number of AI; pregnancies per AI) to first AI for cows with different calving status (carryover $=$ cows that calved the year before, early calving, or late calving). The conception rate increased with cows that were carryover or calved early $(P<0.001)$. The interaction of calving status and treatment was not significant. 14dCIDR_TAI $=$ controlled internal drug release (CIDR) device in for $14 \mathrm{~d}$, CIDR out, $\mathrm{PGF}_{2}$ injection at $19 \mathrm{~d}$ after CIDR removal, $\mathrm{GnRH}$ injection $56 \mathrm{~h}$ later, and then timed AI (TAI) $16 \mathrm{~h}$ later; and control $=\mathrm{PGF}_{2 \alpha}$ injection on $\mathrm{d}$ $12, \mathrm{PGF}_{2 \alpha}$ treatment again to cows with no estrus $7 \mathrm{~d}$ later, CIDR to cows with no estrus after the first or second $\mathrm{PGF}_{2 \alpha}$ injection $7 \mathrm{~d}$ later, CIDR out and $\mathrm{PGF}_{2 \alpha}$ treatment again $7 \mathrm{~d}$ later, and $\mathrm{AI}$ after observed estrus.

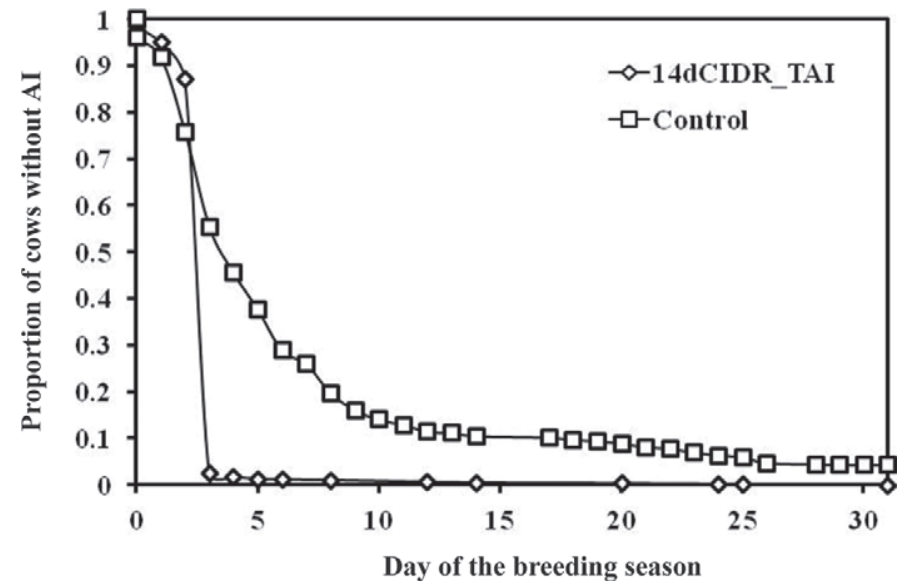

Figure 4. The proportion of cows not artificially inseminated on each day during the breeding season (survival analyses). Cows were assigned to either a 14dCIDR_TAI program [controlled internal drug release (CIDR) for $14 \mathrm{~d}$ to presynchronize the estrous cycle before a timed AI (TAI)] or the control (a $\mathrm{PGF}_{2 \alpha}$-based program to synchronize estrus before AI). Survival curves differed at $P<0.001$. 14dCIDR TAI $=$ CIDR device in for $14 \mathrm{~d}$, CIDR out, PGF $_{2 \alpha}$ injection at $19 \mathrm{~d}$ after CIDR removal, GnRH injection $56 \mathrm{~h}$ later, and then TAI $16 \mathrm{~h}$ later; and control $=\mathrm{PGF}_{2 \alpha}$ injection on $\mathrm{d} 12, \mathrm{PGF}_{2 \alpha}$ treatment again to cows with no estrus $7 \mathrm{~d}$ later, CIDR to cows with no estrus after the first or second $\mathrm{PGF}_{2 \alpha}$ injection $7 \mathrm{~d}$ later, CIDR out and $\mathrm{PGF}_{2 \alpha}$ treatment again $7 \mathrm{~d}$ later, and $\mathrm{AI}$ after observed estrus. 


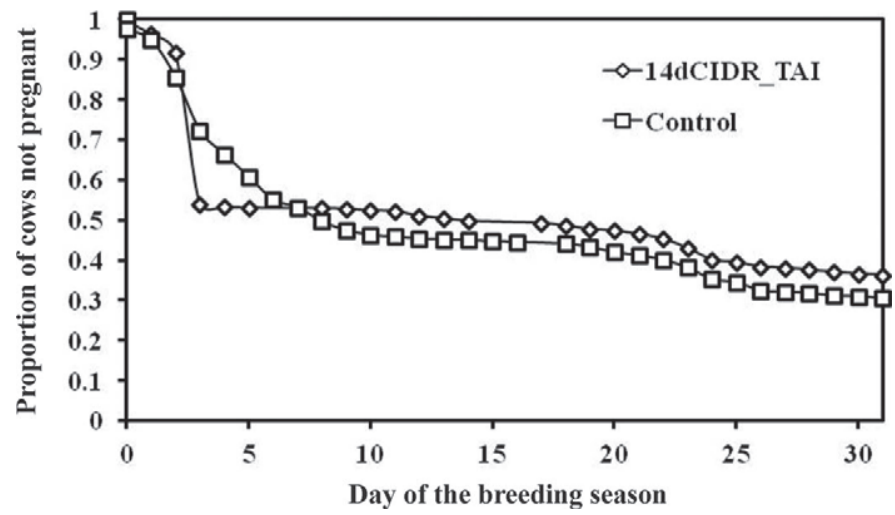

Figure 5. The proportion of cows not pregnant on each day during the breeding season (survival analyses). Cows were assigned to either a 14dCIDR_TAI program [controlled internal drug release (CIDR) for $14 \mathrm{~d}$ to presynchronize the estrous cycle before a timed AI (TAI)] or the control (a $\mathrm{PGF}_{2 \alpha}$-based program to synchronize estrus before AI). Survival curves differed at $P<0.01 .14 \mathrm{dCIDR} \_$TAI $=$CIDR device in for $14 \mathrm{~d}$, CIDR out, $\mathrm{PGF}_{2 \alpha}$ injection at $19 \mathrm{~d}$ after CIDR removal, GnRH injection $56 \mathrm{~h}$ later, and then TAI $16 \mathrm{~h}$ later; and control = $\mathrm{PGF}_{2 \alpha}$ injection on d $12, \mathrm{PGF}_{2 \alpha}$ treatment again to cows with no estrus $7 \mathrm{~d}$ later, CIDR to cows with no estrus after the first or second $\mathrm{PGF}_{2 \alpha}$ injection $7 \mathrm{~d}$ later, CIDR out and $\mathrm{PGF}_{2 \alpha}$ treatment again $7 \mathrm{~d}$ later, and $\mathrm{AI}$ after observed estrus.

$\mathrm{d}$, followed by $\mathrm{PGF}_{2 \alpha}$ injection to synchronize estrus (reviewed by Patterson et al., 1989). The 14dCIDR program has been used for beef heifers and beef cows (Schafer et al., 2007; Leitman et al., 2009), but this is an initial study in which the program was tested in dairy cows. The 14dCIDR_TAI program did not surpass the control program in FSCR (48 vs. $61 \%$, respectively). A tendency existed for a treatment by farm interaction $(P<0.10)$ for FSCR, but this appeared to be caused by 1 farm with relatively few cows (farm number 4 ). Larger farms (1 to 3 ) had a 10- to 20-percentage point lesser FSCR for the 14dCIDR_TAI program compared with the control program (Table 1 ). The 2 programs did have comparable pregnancy rates after 2 AI (64 vs. $70 \%$, respectively; Table 1 ).

Cows with a BCS of 3.0 (approximately $12 \%$ of the study cows) had an FSCR of $62 \%$ that was about 12 percentage points greater than cows with $\mathrm{BCS}=2.0$ (50\% FSCR). As BCS increases, conception rate to first $\mathrm{AI}$ is expected to increase. A cow's BCS, therefore, is predictive of FSCR success (Santos et al., 2009). Although treatment interactions were not significant, the greatest disadvantage in terms of TAI FSCR relative to the control occurred for cows that were either low $\mathrm{BCS}$ (BCS $=2$ or 2.5 ) or late calving (Figures 2 and 3 ). This is perhaps because all cows, including those that were not cycling, were inseminated within the TAI program. Cows with low BCS and late-calving cows are more likely to be noncycling (Short et al., 1990; Santos et al., 2009). These cows that are inseminated in a TAI program but are not inseminated in an estrusbased program can lead to a reduction in FSCR for TAI compared with AI after observed estrus. Calving status may be another indicator of FSCR success. Cows that were carryover or calved early in the calving season had a greater FSCR (55 and 61\%, respectively) compared with cows that calved late in the calving season (41\%). Perhaps this is due to the increase in days postpartum for the carryover and early calved cows. Greater days postpartum would allow more time for uterine involution and more time to overcome the anestrous period and the period of short estrous cycles postpartum (Short et al., 1990). One limitation of the current study is that we did not evaluate the cows for estrous cyclicity (cyclic vs. anovular), the completeness of uterine involution, or uterine health (diseased vs. healthy uterus) before the start of the trial. We cannot, therefore, confirm that the differences in FSCR associated with either BCS or time of calving were indeed associated with a greater proportion of cyclic cows, a more complete uterine involution, or a lower incidence of uterine disease. Future studies should evaluate the efficacy of the respective programs relative to the cyclicity status, the state of uterine involution, and the uterine health of cows entering the programs.

Pursley et al. (1997b) demonstrated that no difference existed in lactating dairy cows in pregnancy rate between those cows that had a TAI or AI after estrus. The 14dCIDR_TAI program had an initial advantage because more cows were artificially inseminated (Figure 4) and became pregnant (Figure 5) early in the breeding season compared with the control program. By d 5 of the breeding season, for example, almost all of the 14dCIDR_TAI cows were inseminated compared with $62 \%$ of the controls that were inseminated by $\mathrm{d} 5$. One limitation of programs based solely on estrus detection is that some cows are never inseminated (Pursley et al., 1997a). We observed this in our trial where $4 \%$ $(25 / 626)$ of the control cows were never inseminated (Figure 4). Despite this advantage in insemination rate, the 14dCIDR_TAI program was not superior in terms of pregnancies (Figure 5). The slightly reduced TAI FSCR led to fewer pregnancies initially. These fewer initial pregnancies were never recaptured as the breeding season progressed (i.e., the initial advantage of the control program was maintained for at least 31 d; Figure 5).

One unique aspect of this trial was the enrollment of seasonal grass-based dairies for the purpose of reproductive studies. These dairies, all within $100 \mathrm{~km}$ of Springfield, Missouri, had milk production of approximately $25 \mathrm{~kg}$ per cow per day. The TAI cows enrolled in the trial were artificially inseminated within a $4-d$ period for the 4 farms and control cows were artificially 
inseminated within the same month (most cows were artificially inseminated in May). The FSCR for all farms exceeded $50 \%$ (Table 1) and the overall pregnancies $(2$ AI) were greater than $65 \%$. One farm (number 3 ) had a $66.8 \%$ FSCR and a pregnancy rate of $80 \%$ after 2 AI. Differences in fertility between the individual farms may represent unique aspects of the farms, including genetics, nutrition, and herd health programs, which were not controlled in this study. Age structure of the individual herds did not appear to be a factor because first-parity cows ( $28 \%$ of study animals) were similar to older cows for FSCR (56 vs. $52 \% ; P>0.10$ ) and no interaction existed between treatment and age (i.e., the control program was superior to $14 \mathrm{dCIDR}$ _TAI in both first-parity and multiparous cows). Despite the relatively good reproduction, the farms could perhaps improve in terms of pregnancies from second insemination. Careful examination of Figure 5 reveals that although $>50 \%$ of cows were pregnant after first insemination, the herds achieved very few pregnancies for second insemination (d 20 to 25 of the breeding season). The herds may potentially benefit from programs specifically designed for use at second insemination for cows that are not pregnant after first AI.

\section{CONCLUSIONS}

The 14dCIDR_TAI program cows were artificially inseminated early in the breeding season and were all artificially inseminated by the end the breeding season. The control program had fewer cows artificially inseminated early in the breeding season and not all cows received AI. The 14dCIDR_TAI program had a lesser FSCR compared with the control (AI at estrus) and the initial advantage of more pregnancies early in the breeding season was not maintained over time. Synchronization of ovulation with the 14dCIDR_TAI program achieved comparable pregnancy rates after 2 AI compared with a control program (synchronization of estrus and AI). Cows that had a BCS of 3.0 were more likely to become pregnant compared with cows that had a BCS of 2.0. Cows that were carryover or early calving were more likely to become pregnant compared with cows that calved later in the calving season. Overall, synchronization of ovulation before TAI may improve reproductive efficiency in herds by decreasing the dependency on estrus detection and achieving more pregnancies early in the breeding season. To be effective, the TAI conception rate must exceed the combined effects of estrus detection efficiency and superior conception rate after AI at estrus.

\section{REFERENCES}

Ahmad, N., F. N. Schrick, R. L. Butcher, and E. K. Inskeep. 1995. Effect of persistent follicles on early embryonic losses in beef cattle. Biol. Reprod. 52:1129-1135.

Bello, N. M., J. P. Steibel, and J. R. Pursley. 2006. Optimizing ovulation to first GnRH improved outcomes to each hormonal injection of Ovsynch in lactating dairy cows. J. Dairy Sci. 89:3413-3424.

Cavalieri, J., G. Hepworth, L. A. Fitzpatrick, R. W. Shepard, and K. L. Macmillan. 2006. Manipulation and control of the estrous cycle in pasture-based dairy cows. Theriogenology 65:45-64.

Giordano, J. O., M. C. Wiltbank, J. N. Guenther, R. Pawlisch, S. Bas, A. P. Cunha, and P. M. Fricke. 2012. Increased fertility in lactating dairy cows resynchronized with Double-Ovsynch compared with Ovsynch initiated $32 \mathrm{~d}$ after timed artificial insemination. J. Dairy Sci. 95:639-653.

Leitman, N. R., D. C. Busch, D. A. Mallory, D. J. Wilson, M. R Ellersieck, M. F. Smith, and D. J. Patterson. 2009. Comparison of long-term CIDR-based protocols to synchronize estrus in beef heifers. Anim. Reprod. Sci. 114:345-355.

Lucy, M. C., S. McDougall, and D. P. Nation. 2004. The use of hormonal treatments to improve the reproductive performance of lactating dairy cows in feedlot or pasture-based management systems. Anim. Reprod. Sci. 82-83:495-512.

Macmillan, K. L. 2010. Recent advances in the synchronization of estrus and ovulation in dairy cows. J. Reprod. Dev. 56:S42-S47.

Moreira, F., C. Orlandi, C. A. Risco, R. Mattos, F. Lopes, and W. W. Thatcher. 2001. Effects of presynchronization and bovine somatotropin on pregnancy rates to a timed artificial insemination protocol in lactating dairy cows. J. Dairy Sci. 84:1646-1659.

Patterson, D. J., G. H. Kiracofe, J. S. Stevenson, and L. R. Corah. 1989. Control of the bovine estrous cycle with melengestrol acetate (MGA): A review. J. Anim. Sci. 67:1895-1906.

Pursley, J. R., M. R. Kosorok, and M. C. Wiltbank. 1997a. Reproductive management of lactating dairy cows using synchronization of ovulation. J. Dairy Sci. 80:301-306.

Pursley, J. R., M. C. Wiltbank, J. S. Stevenson, J. S. Ottobre, H. A. Garverick, and L. L. Anderson. 1997b. Pregnancy rates per artificial insemination for cows and heifers inseminated at a synchronized ovulation or synchronized estrus. J. Dairy Sci. 80:295-300.

Revah, I., and W. R. Butler. 1996. Prolonged dominance of follicles and reduced viability of bovine oocytes. J. Reprod. Fertil. 106:39-47.

Ribeiro, E. S., R. L. A. Cerri, R. S. Bisinotto, F. S. Lima, F. T. Silvestre, L. F. Greco, W. W. Thatcher, and J. E. P. Santos. 2011. Reproductive performance of grazing dairy cows following presynchronization and resynchronization protocols. J. Dairy Sci. 94:4984-4996.

Roche, J. F., E. J. Austin, M. Ryan, M. O'Rourke, M. Mihm, and M. G. Diskin. 1999. Regulation of follicle waves to maximize fertility in cattle. J. Reprod. Fertil. Suppl. 54:61-71.

Santos, J. E. P., H. M. Rutigliano, and M. F. Sá Filho. 2009. Risk factors for resumption of postpartum estrous cycles and embryonic survival in lactating dairy cows. Anim. Reprod. Sci. 110:207-221.

Schafer, D. J., J. F. Bader, J. P. Meyer, J. K. Haden, M. R. Ellersieck, M. C. Lucy, M. F. Smith, and D. J. Patterson. 2007. Comparison of progestin-based protocols to synchronize estrus and ovulation before fixed-timed artificial insemination in postpartum beef cows. J. Anim. Sci. 85:1940-1945.

Short, R. E., R. A. Bellows, R. B. Staigmiller, J. G. Berardinelli, and E. E. Custer. 1990. Physiological mechanisms controlling anestrus and infertility in postpartum beef cattle. J. Anim. Sci. 68:799-816. 